\title{
Correction to: Identification of metals and alloys using color CCD images of laser-induced breakdown emissions coupled with machine learning
}

\author{
Linga Murthy Narlagiri ${ }^{1} \cdot$ S. Venugopal Rao ${ }^{1}$ (i)
}

Published online: 7 July 2020

(c) Springer-Verlag GmbH Germany, part of Springer Nature 2020

\section{Correction to: https://doi.org/10.1007/s0034 \\ 0-020-07469-6}

Unfortunately, the first author name was incorrectly published in the original publication. The compete correct name should read as follows.

Linga Murthy Narlagiri.

Publisher's Note Springer Nature remains neutral with regard to jurisdictional claims in published maps and institutional affiliations.

The original article can be found online at https://doi.org/10.1007/ s00340-020-07469-6.

S. Venugopal Rao

soma_venu@uohyd.ac.in; soma_venu@yahoo.ac.in

1 Advanced Centre of Research in High Energy Materials (ACRHEM), University of Hyderabad, Hyderabad, Telangana 500046, India 